\title{
An anfis converter control approach of grid connected wind/PV/battery system
}

\author{
R. Arulmurugan, Swapna Sandaraju \\ Deptartment of EEE, S R Engineering College, Warangal. TS, India
}

\begin{tabular}{l}
\hline \hline Article Info \\
\hline Article history: \\
Received Jan 7, 2019 \\
Revised Feb 14, 2019 \\
Accepted Feb 28, 2019 \\
\hline
\end{tabular}

\section{Keywords:}

ANFIS controller

Battery

DC-DC converter

Hybrid system

MPPT

PV

Wind

\begin{abstract}
The major objective of this task is a control technique for power flow management of a network associated hybrid PV-wind-battery based system with multi-input transformer coupled bidirectional dc-dc converter using ANFIS controller is introduced. The proposed system intends to fulfill the demand of load, deal with the power flow from the distinctive sources, injects surplus power into the network and charge the battery from framework as and when required. A transformer coupled boost half-bridge converter is used to tackle power from wind, while bidirectional buck-boost converter is used to outfit control from PV alongside battery charging/releasing control. A single stage full-bridge bidirectional converter is used for ac loads and collaboration with grid. The proposed converter has reduced number of intensity change stages. This enhances the effectiveness and unwavering quality of the framework. In this article Adaptive Neuro Fuzzy interference System (ANFIS) is proposed for better performance of the system. Neural system has many inputs and also has multiple outputs but the fuzzy logic has multiple inputs and single output, so the combination of this two is known as ANFIS which is utilized for nonlinear applications. The proposed paper of simulation results acquired using MATLAB/Simulink demonstrate the execution of the proposed control procedure for power stream the executives under different methods of activity.
\end{abstract}

Copyright $@ 2019$ Institute of Advanced Engineering and Science. All rights reserved.

\section{Corresponding Author:}

Swapna Sandaraju

Deptartment of EEE,

S R Engineering College,

Warangal. TS, India.

Email: Swapna.sandaraju@gmail.com, arul.lect@gmail.com

\section{INTRODUCTION}

Solar based photovoltaic (PV) and wind have ascended as popular imperativeness sources due to their eco-pleasing nature and cost reasonability. Nevertheless, these sources are unpredictable in nature. From this time forward, it is test to supply consistent and determined power using these sources. This can be tended to by capably joining with imperativeness amassing segments. The fascinating correlative lead of sun controlled insolation and wind speed configuration joined with the recently referenced focal points, has provoked the examination on their joining achieving crossbreed PV-wind frameworks [1]. For achieving the compromise of various endless sources, the standard technique incorporates using submitted single-input converters one for each source, which are related with a regular dc-transport [2]. Regardless, these converters are not enough utilized, on account of the spasmodic thought of the unlimited sources. Additionally, there are different power change stages which lessen the capability of the framework. Colossal proportion of composing exists on the coordination of sun based and curve imperativeness as a crossbreed essentialness age framework with spotlight fundamentally on its evaluating and progression. In the estimating of generators in a cream framework is investigated [3-7]. In this framework, the sources and limit are interfaced 
at the dc-associate, through their submitted converters.Other duties are made on their showing edges and control techniques for an autonomous creamer imperativeness framework [8-12].

Dynamic execution of an autonomous cross breed PV-wind structure with battery amassing is dismembered. In an inertness/sliding mode control is presented which controls the assignment of wind imperativeness structure to enhance the sun fueled essentialness making framework. Not very many undertakings are made to upgrade the circuit con-figuration of these systems that could diminish the cost and addition the adequacy and trustworthiness. Joined converters for PV and wind imperativeness frameworks are presented. PV-wind hybrid framework, proposed by Daniel et al., has an essential power topology anyway it is proper for stay lone applications. A fused four-port topology subject to blend PV-wind system is proposed. In any case, notwithstanding essential topology the control plot used is amazing. Feed the dc stacks, a low limit multi-port converter for a multi system is displayed. Crossbreed PV-wind based period of intensity and its interface with the power organize are the basic research zones have proposed a multi-input hybrid PV-wind control age system which has a buck/buck-help entwined multi-input dc-dc converter and a full-associate dc-cooling inverter. This system is mainly revolved around upgrading the dc-interface voltage control. In the six-arm converter topology proposed by H. C. Chiang et al. [3], the yields of a PV group and wind generators are urged to a lift converter to arrange the dc-transport voltage. The steady state execution of a structure related PV is inspected in [13]. This paper revolves around system working, for instance, essentialness creation, structure immovable quality, unit evaluating, and cost examination. In a blend PVwind system close by a battery is shown, in which the two sources are related with a commonplace dctransport through individual power converters. In addition, the dc-transport is related with the utility system through an inverter. The use of multi-input converter (MIC) for cross breed control structures is pulling in extending thought in perspective of decreased part check, overhauled control thickness, conservativeness and united control. In light of these good conditions, various topologies are proposed and they can be described into three social affairs, non-disengaged, totally separated and for the most part detached multi-port topologies [13-15].

The structure related cross breed PV-wind-battery based system for nuclear family applications is showed up in Figure 1, which can work either in stay lone or system related mode. This system is sensible for nuclear family applications, where a negligible exertion, clear and littler topology prepared for self-decision movement is alluring. The focal point of the proposed system is the multi-input transformer coupled bidirectional dc-dc converter that interconnects diverse power sources and the limit segment. Further, a control plot for feasible power stream the administrators to give persistent power supply to the stores, while injecting wealth control into the system is proposed [12, 16-20]. Thusly, the proposed plan and control scheme give a choice blend of PV and wind imperativeness source. It has the going with focal points: MPP following of both the sources, Battery charging control and bidirectional power stream are drilled with six switches.

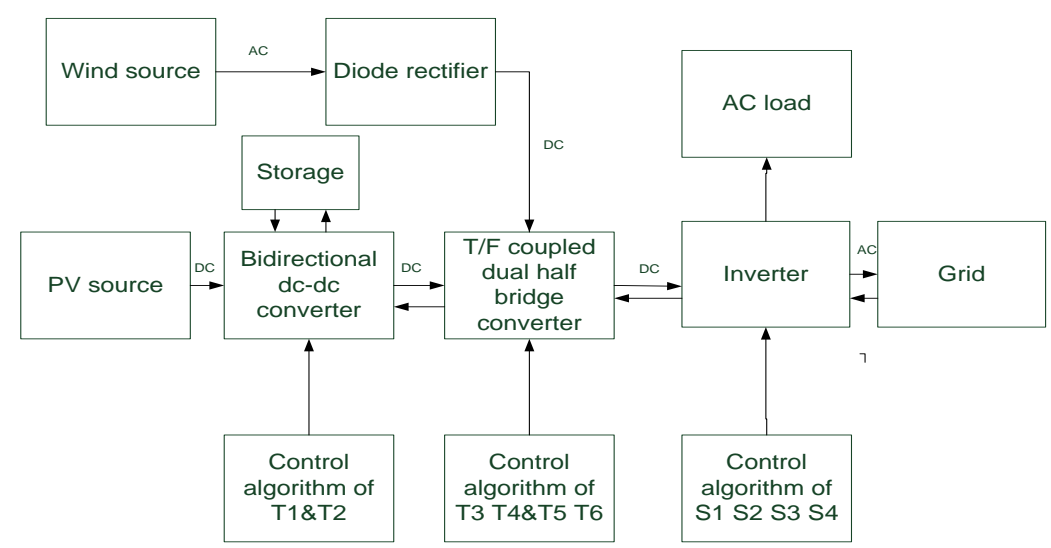

Figure 1. Grid-connected hybrid PV-wind-battery based system for household applications

\section{PROPOSED CONVERTER CONFIGURATION}

The proposed converter contains a transformer coupled boost double half-associate bidirectional converter combined with bidirectional buck-boost converter and a single stage full-interface inverter. The proposed converter has reduced number of power voltage boosting are developed through a single converter. Transformer coupled boost half-bridge converter is used for equipping power from wind and a 
single stage full-interface bidirectional converter is used for reinforcing ac loads and interaction with system. The proposed converter has diminished number of power change stages with less sections and high adequacy compared to present structure related converters.

Exactly when switch T3 is ON, the present coursing through the source inductor increases. The capacitor $\mathrm{C} 1$ discharges through the transformer basic and switch T3. In helper side capacitor C3 charges through transformer discretionary and threatening to parallel diode of switch T5. Exactly when switch T3 is murdered and T4 is turned ON, at first the inductor current courses through adversary of parallel diode of switch T 4 and through the capacitor bank. In the midst of this between time, the present coursing through diode lessens and that travels through transformer fundamental augmentations. Right when current going through the inductor winds up proportional to that traveling through transformer basic. Since, T 4 is gated ON amid this time, the capacitor C6 now discharges through switch T 4 and transformer basic. Amid the ON time of T 4, against parallel diode of switch T 6 practices to charge the capacitor C4. During the ON time of $\mathrm{T} 3$, the fundamental voltage $\mathrm{VP}=-\mathrm{VC} 1$. The assistant voltage $\mathrm{VS}=\mathrm{nVp}=-\mathrm{nVC1}=-\mathrm{VC} 3$, or $\mathrm{VC} 3=\mathrm{nVC1}$ and voltage across over basic inductor Lw is Vw. Exactly when $\mathrm{T} 3$ is executed and T4 turned $\mathrm{ON}$, the basic volt-age $\mathrm{VP}=\mathrm{VC} 2$. Assistant voltage $\mathrm{VS}=\mathrm{nVP}=\mathrm{nVC} 2=\mathrm{VC} 4$ and voltage across over basic inductor $\mathrm{Lw}$ is $\mathrm{Vw}-(\mathrm{VC} 1+\mathrm{VC} 2)$. Change stages with less and high adequacy contrasted and the present system related plans. The topology is direct and needs only six power switches. The lift twofold halfassociate converter has two dc-interfaces on both it can be shown that (1).

$$
(\mathrm{VC} 1+\mathrm{VC} 2)=\frac{\mathrm{Vw}}{(1-\mathrm{Dw})}
$$

The capacitor voltages are seen as predictable in constant state and they settle at VC $3=n V C 1$, VC4 $=$ nVC2. Controlling the voltage of one of the dc-joins, ensures controlling the voltage of the other. This makes the control framework direct. In addition, additional converters can be facilitated with any of the two dc-joins. A bidirectional buck-bolster dc-dc converter is composed with the basic side dc-association and single-organize full-interface bidirectional converter is related with the dc-association of the helper side. The commitment of the half-associate converter is molded by interfacing the PV group in course of action with the battery, along these lines solidifying a trademark boosting stage for the arrangement. The boosting capacity is furthermore enhanced by a high repeat adventure up transformer. The transformer furthermore ensures galvanic separation to the pile from the sources and the battery. Bidirectional buck-help converter is used to equip control from PV close by battery charging/discharging control. The unique part of this converter is that MPP following, battery charge control and in this way, the yield voltage of the assistant side dc-interface is a component of the commitment cycle of the fundamental side converter and turns extent of transformer.

In proposed plan as showed up in Figure 2, a bidirectional buck-bolster converter is used for MPP following of PV bunch and battery charging/discharging control. Further, this bidirectional buck-help converter charges/discharges the capacitor bank C1-C2 of transformer coupled half-interface bolster converter reliant on the load asks. The half-associate help converter removes imperativeness from the breeze source to the capacitor bank $\mathrm{C} 1-\mathrm{C} 2$. In the midst of battery charging mode, when switch $\mathrm{T} 1$ is $\mathrm{ON}$, the essentialness is secured in the inductor L. Right when switch T1 is executed and T2 is turned ON, essentialness set away in L is traded to the battery. In case the battery discharging current is more than the PV current, inductor current winds up negative.

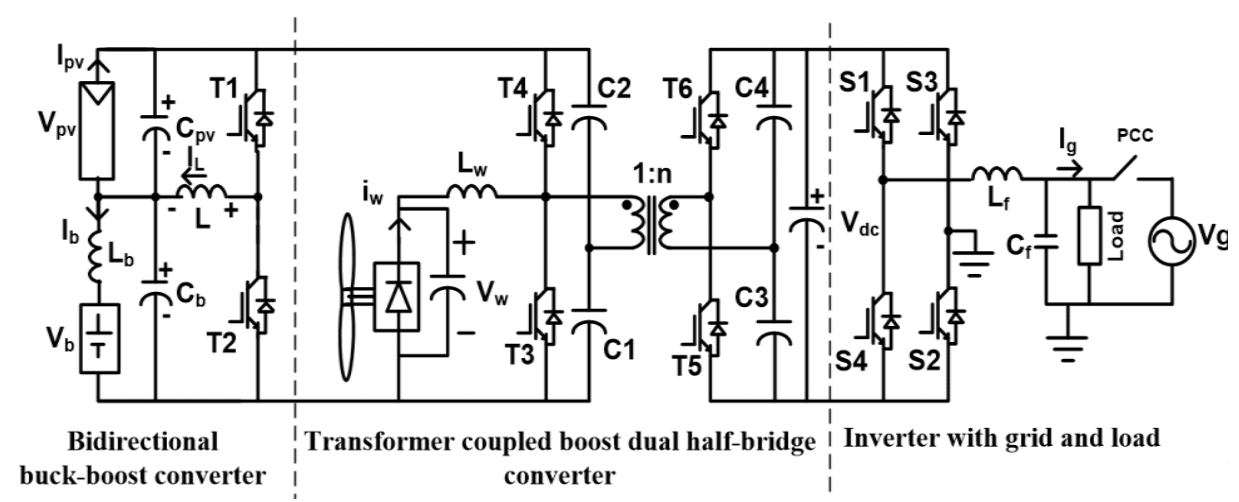

Figure 2. Proposed converter configuration 
Here, the stored energy in the inductor increases when T2 is turned on and decreases when T1 is turned on. It can be proved that (2).

$$
V_{b}=\frac{D}{1-D} V_{P v}
$$

The controlling scheme of the proposed system is shown in Figure 3.
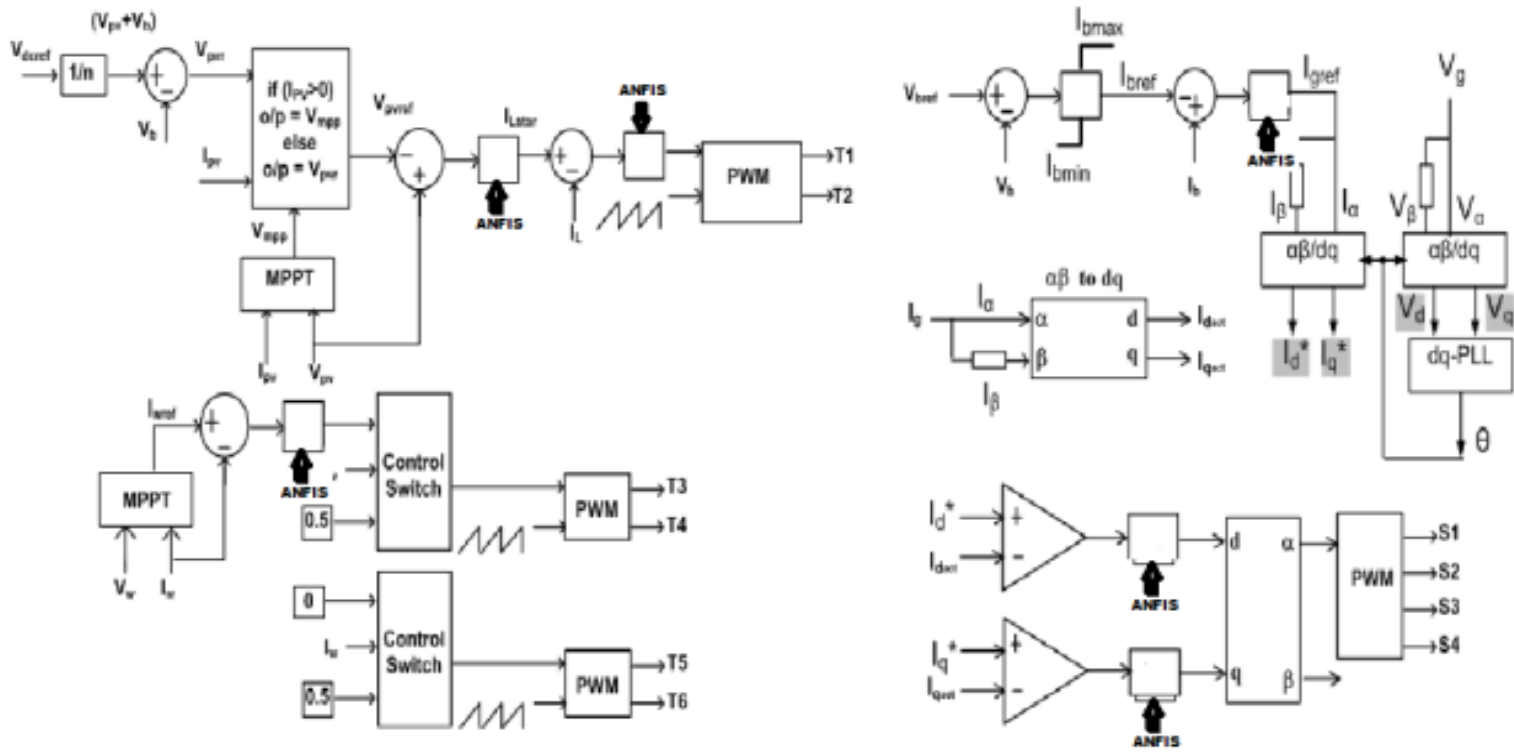

Figure 3. Proposed control scheme for power flow management of a grid- connected hybrid PV wind-battery based system

The output voltage of the transformer coupled boost half-bridge converter is given by (3),

$$
V_{d c}=n\left(V_{C 1}+V_{C 2}\right)=n\left(V_{b}+V_{P V}\right)=\frac{n V_{w}}{1-D_{w}}
$$

This voltage is $\mathrm{n}$ times of basic side dc-interface voltage. The basic side dc-interface voltage can be controlled extensively associate help converter or by bidirectional buck-encourage converter. The association between the typical estimation of inductor, PV and battery current over a trading cycle is given by $\mathrm{IL}=\mathrm{Ib}+\mathrm{Ipv}$. Clearly, Ib and Ipv can be controlled by controlling IL. Consequently, the MPP movement is ensured by controlling IL.

\subsection{ANFIS control System}

Fuzzy Logic Control (FLC) method is commonly used in control systems based on micro processors, because it does not necessitate an exact model of the system and is insensitive to variations of operating points and parameters. It is based on rule basis and Membership Functions (MF), which are generally obtained by a trial-and-error method and consequently it is a time-consuming and error-prone procedure.

Artificial Neural Networks (ANNs) are mathematical models with parallel data processing and learning abilities, which utilize computational neurons (nonlinear cells) structured in layers and linked to each other by weight factors. ANN's are also used in microprocessor control systems owing to their nonlinear and generalization skills, adaptive structure, and independent design from system parameters. However, their drawbacks are the instruction problem of network and lack of rules for defining the structure due to their "black box" nature. FLC and ANNs are complementary schemes in the design of intelligent control systems. With ANN systems, the development time is reduced and the accuracy of the fuzzy model is enhanced.

Two general fuzzy models are Mamdani and Takagi Sugeno-Kang (TSK) defined for FIS. The ANFIS is capable to use only the TSK fuzzy model due to adaptive techniques, its elevated calculative efficiency and built in most favorable. The ANFIS structure is shown in Figure 4. 


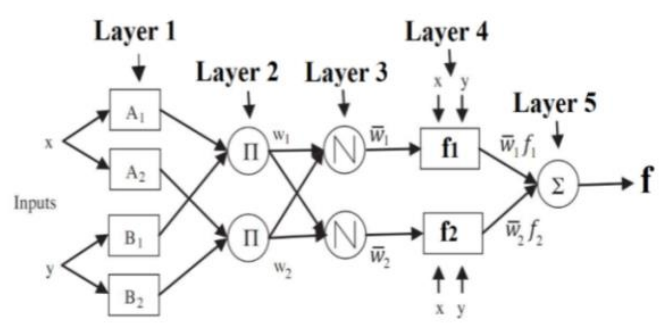

Figure 4. Structure of ANFIS

Generally, ANFIS is different layer feed forward system with stable output in which every node performs a node function on incoming signals. For convenience, we consider two inputs ' $x$ ' and ' $y$ ' and one output ' $z$ '. Assume that the rule base ensure the Takagi and Sugeno type two fuzzy if-then rules.

Rule 1: IF $\mathrm{x}$ is $\mathrm{A} 1$ and $\mathrm{y}$ is $\mathrm{B} 1 \mathrm{THEN} \mathrm{f} 1=\mathrm{P} 1 \mathrm{x}+\mathrm{Q} 1 \mathrm{y}+\mathrm{R} 1$

Rule 2: IF $\mathrm{x}$ is $\mathrm{A} 2$ and $\mathrm{y}$ is $\mathrm{B} 2$ THEN $\mathrm{f} 2=\mathrm{P} 2 \mathrm{x}+\mathrm{Q} 2 \mathrm{y}+\mathrm{R} 2$

The ANFIS structure is a five layer feed forward network given as:

Step 1: In this layer every node is a square node by a node function (the membership value of the premise part) $\mathrm{Oi}=\mu \mathrm{Ai}(\mathrm{X})$. Where, $\mathrm{x}$ is the input to the node $\mathrm{i}$, and $\mathrm{Ai}$ is the linguistic label related with this node function.

Step 2: Every node in this layer is a circle node labeled which multiplies the incoming signals. Each node output represents the firing strength of a rule. $\mathrm{Oi} 2=\mu \mathrm{Ai}(\mathrm{X}) \mu \mathrm{Bi}(\mathrm{Y})$, where $\mathrm{i}=1: 2$.

Step 3: In this layer every node is a circle node labeled $\mathrm{N}$ (normalization). The ith node calculates the ratio of the ith rule's firing strength to the sum of all firing strengths. Oi3=W1/(W1+W2, where $i=1: 2$.

Step 4: Every node in this layer is a square node with a node function Oi4=W (PiX+QiY+Ri).

Step 5: The single node in this layer is a circle node labeled that computes the overall output as the summation of all incoming signals, Oi5 = System output, where $\mathrm{i}=1: 2$

\section{SIMULATION RESULTS}

In the Figure 5 shows the simulink diagram with ANFIS controller, Figure 6 shows the control scheme of bidirectional buck-boost converter, in this scheme the maximum power from the PV source can be obtained by using Incremental Conductance method. Control of the switches T1 and T2 will control the power from PV source and battery. The reference block will compare the Vmpp and Ipv with reference voltage and current. The ANFIS controller gives the efficient output and the PWM generator is used to generate the pulses for switches T1 and T2.

Figure 7 shows the control scheme of transformer coupled boost dual half bridge converter, in this scheme the maximum power from the wind source can be obtained by using Incremental Conductance method. Control of the switches T3, T4 and T5, T6 will control the power from wind source. Figure 8 shows the control scheme of 1-phase full bridge inverter integrated to grid, Figure 9 shows steady state operation (Voltage \& Current vs Time), The battery is charged with the constant magnitude of current and remaining power is fed to the grid.
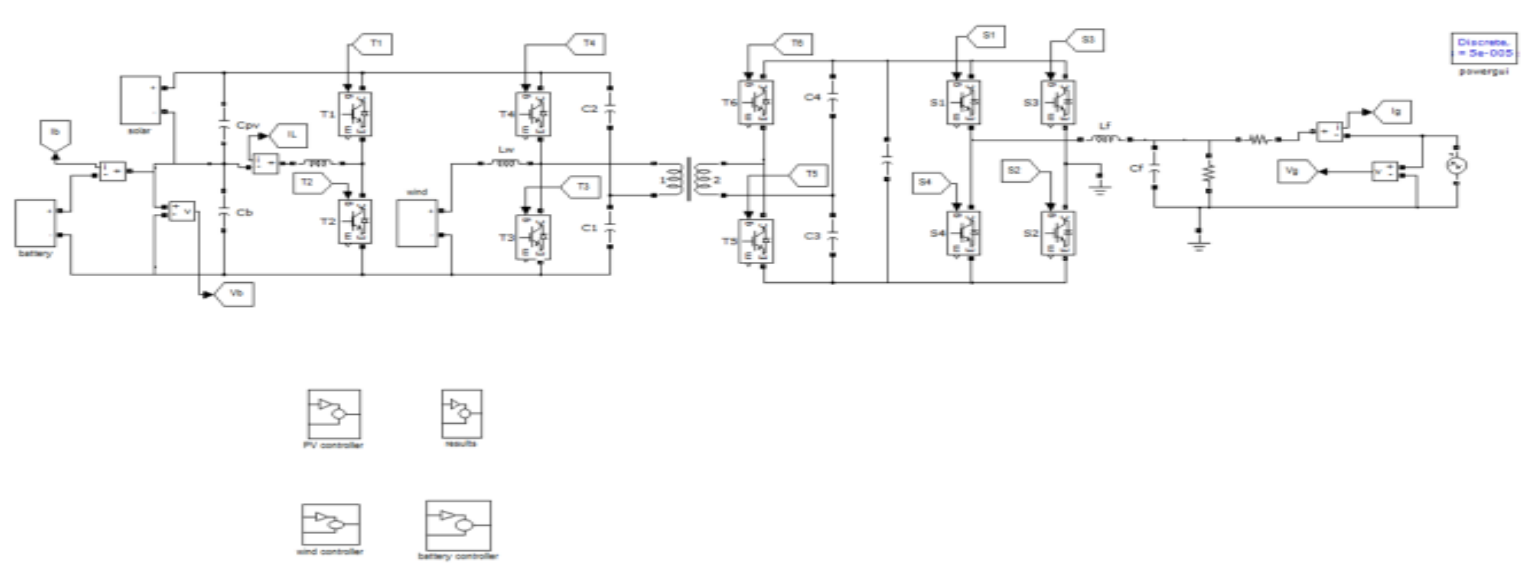

Figure 5. SIMULINK Circuit of PV WIND BATTERY Storage Circuit 


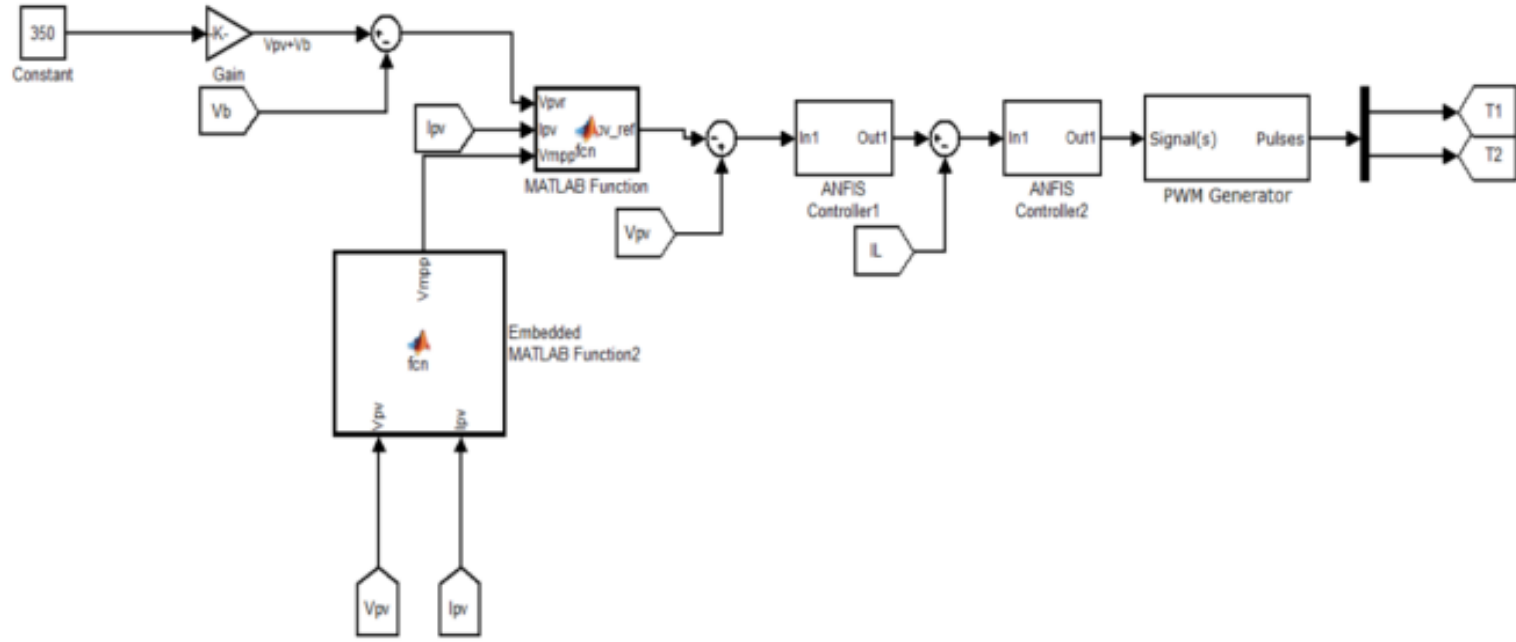

Figure 6. Control scheme of bidirectional buck-boost converter

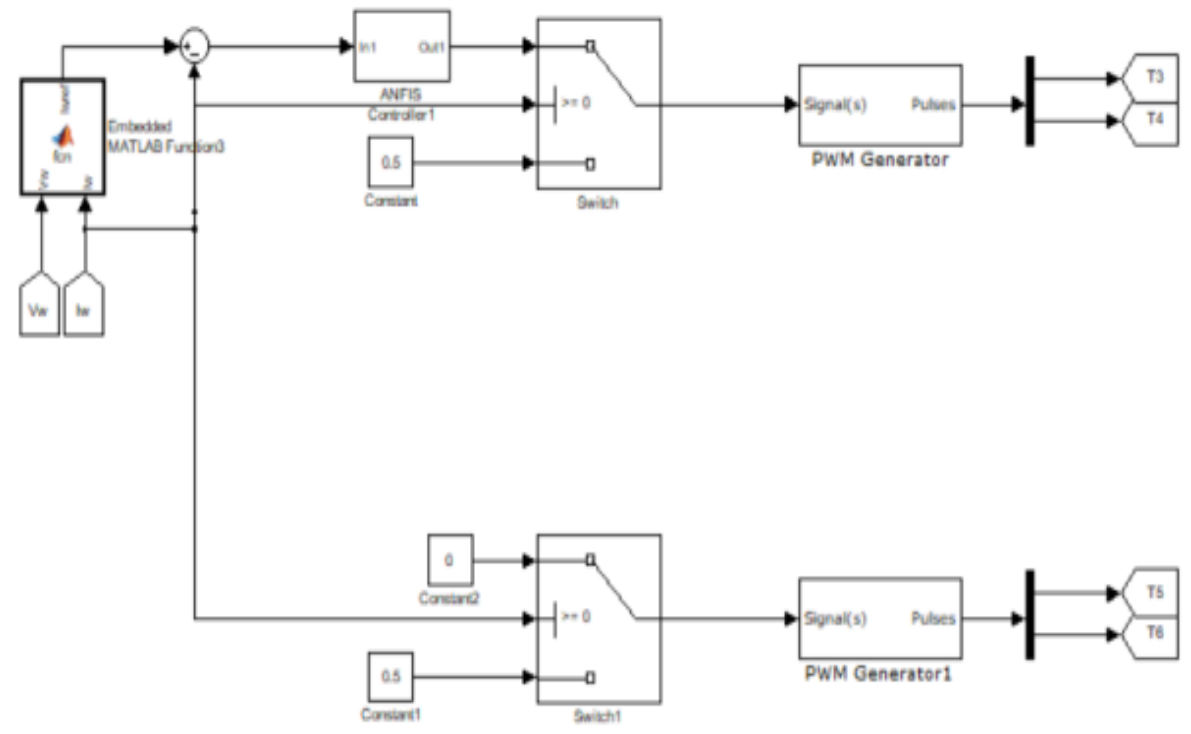

Figure 7. Control scheme of transformer coupled boost dual half bridge converter

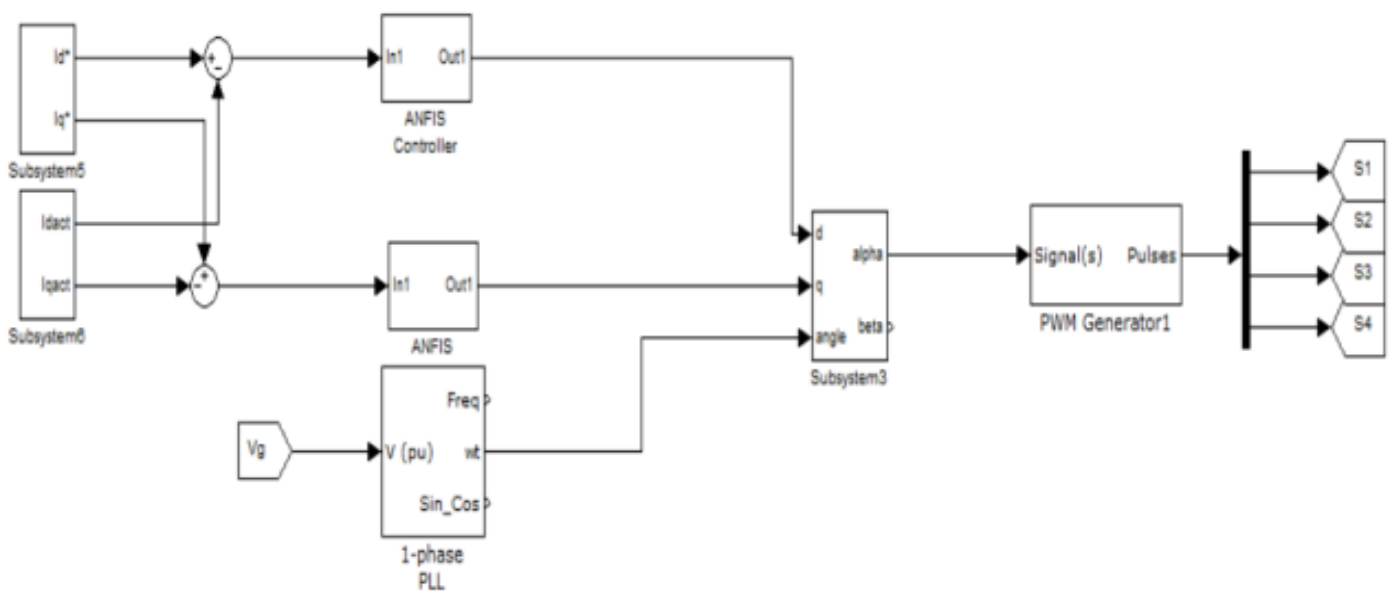

Figure 8. Control scheme of 1-phase full bridge inverter integrated to grid 
Figure 10 shows response of the framework for changes in insolation level of PV source, Until 2s, both sources are working at MPPT and charging the battery by means of constant current and the residual power is fed to the grid. At time $2 \mathrm{~s}$, the PV source insolation level is improved. As a result the PV source power increases and both the sources keep on operate at MPPT. Though the PV array power has increased, the battery is still charged with the same magnitude of current and power balance is achieved by increasing the power supplied to the grid. The Table 1 shows the simulation parameters of the system and Table 2 shows the comparison of THD'S.

Table 1. Simulation parameters

\begin{tabular}{|c|c|c|}
\hline S.No & PARAMETER & VALUE \\
\hline 1. & Solar PV power & $\begin{array}{c}525 \mathrm{~W} \\
(\operatorname{Impp}=14.8 \mathrm{~A})(\mathrm{Vmpp}=35.4 \mathrm{~V})\end{array}$ \\
\hline 2. & Wind power & $\begin{array}{c}300 \mathrm{~W} \\
(\operatorname{Impp}=8 \mathrm{~A})(\mathrm{Vmpp}=37.5 \mathrm{~V})\end{array}$ \\
\hline 3. & Switching frequency & $15 \mathrm{kHz}$ \\
\hline 4. & Transformer turns ratio & 5.5 \\
\hline 5. & Inductor-half bridge boost converter Lw & $500 \mu \mathrm{H}$ \\
\hline 6. & Inductor-bidirectional converter L & $3000 \mu \mathrm{H}$ \\
\hline 7. & Primary side capacitors C1-C2 & $500 \mu \mathrm{F}$ \\
\hline 8. & secondary side capacitors $\mathrm{C} 3-\mathrm{C} 4$ & $500 \mu \mathrm{F}$ \\
\hline 9. & Secondary side capacitor for the entire dc-link & $2000 \mu \mathrm{F}$ \\
\hline 10. & Battery capacity \& voltage & $400 \mathrm{Ah}, 36 \mathrm{~V}$ \\
\hline
\end{tabular}

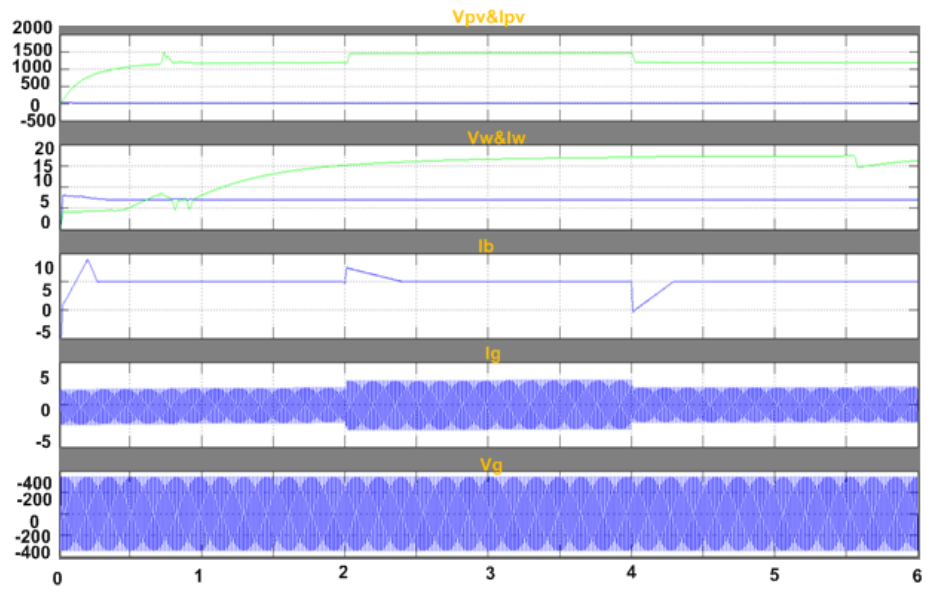

Figure 9. Steady State Operation (Voltage \& Current vs Time)

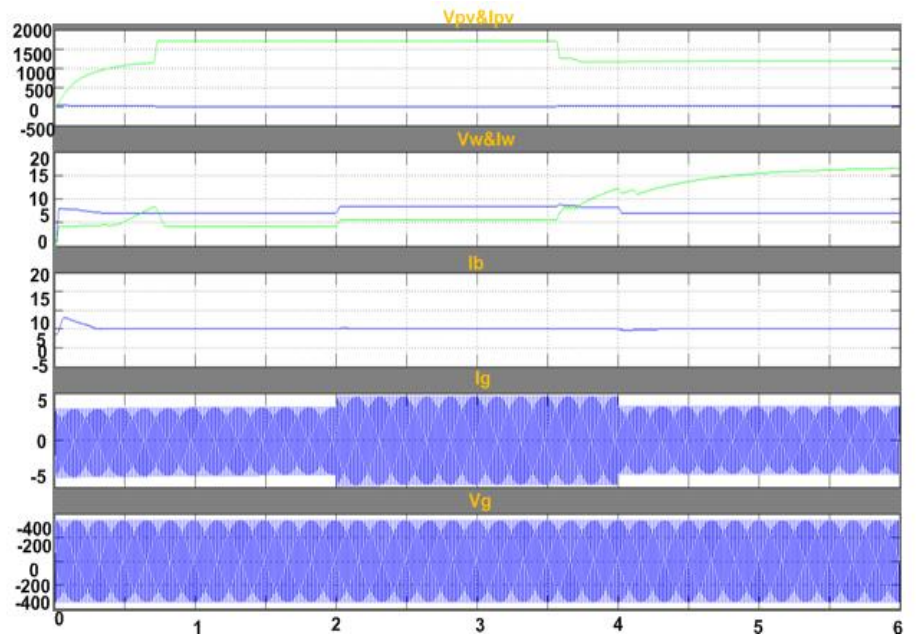

Figure 10. Response of the framework for changes in insolation level of PV source (Voltage \& Current vs Time)

Int J Rob \& Autom, Vol. 8, No. 1, March 2019 : 6-17 
At the time 4s, PV source insolation is brought to the same level as before $2 \mathrm{~s}$. The power is supplied through PV source is decreases. Battery is continued to get charged at the same magnitude of current, and power injected into the grid decreases. Figure 11 shows response of the framework for changes in insolation level of wind source.

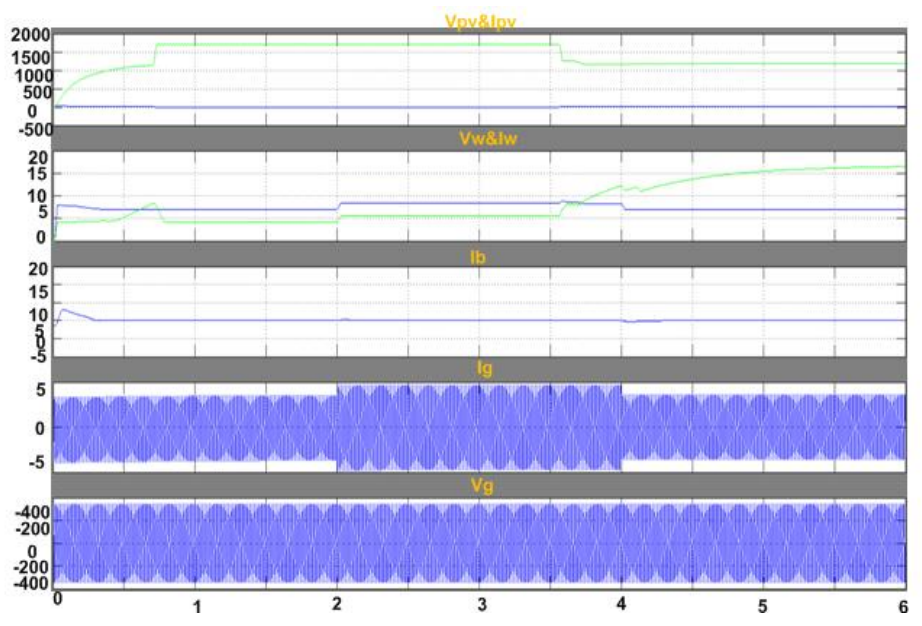

Figure 11. Response of the framework for changes in insolation level of wind source (Voltage \& Current vs Time)

In Figure 12 shows response of the framework in the absence of PV source while wind source continues to operate, Till time $2 \mathrm{~s}$, both the sources are generating the power by working at their corresponding MPPT and charging the battery at constant magnitude of current, and the remaining power is being fed to the grid. At the time 2s, PV source is disconnected from the system. The charging current of the battery remains constant, while the injected power to the grid reduces. At instant 4s, PV source is brought back into the system. There is no change in the charging rate of the battery. The additional power is fed to grid and Figure 13 shows Response of the framework in the absence of wind source while PV source continues to operate and Figure 14 shows response of the framework in the absence of both wind and PV source (Voltage \& Current vs Time).

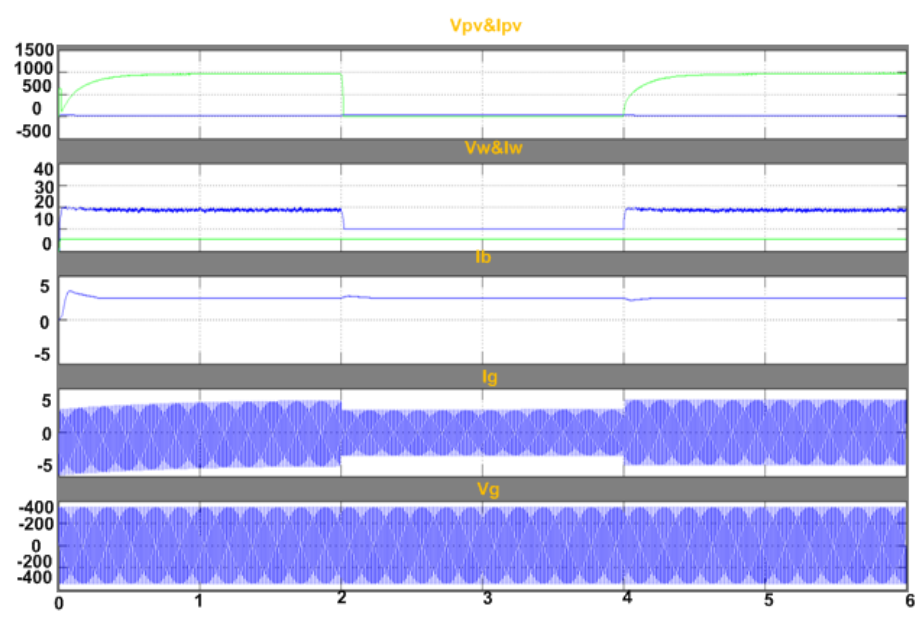

Figure 12. Respons of the framework in the absence of PV source while wind source continues to operate (Voltage \& Current vs Time) 


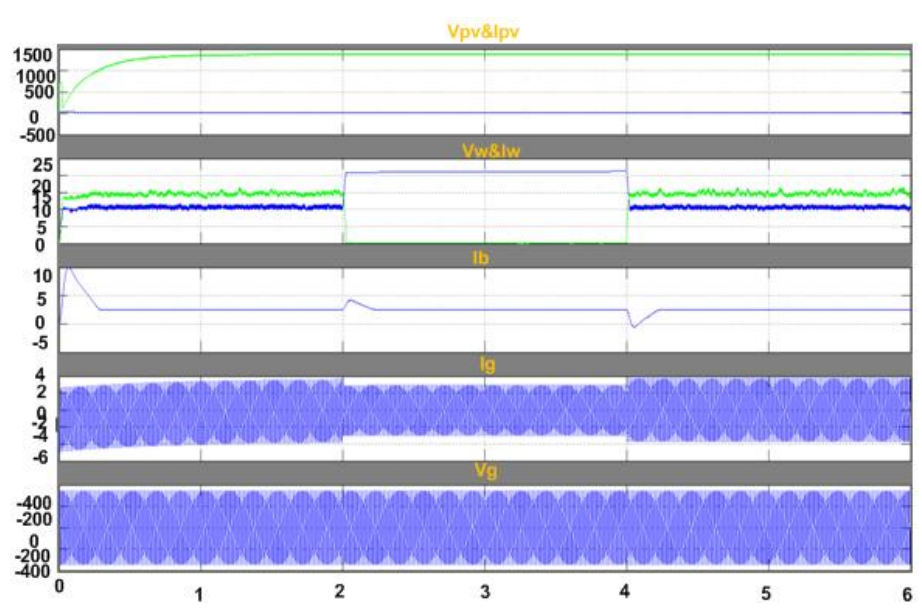

Figure 13. Response of the framework in the absence of wind source while PV source continues to operate (Voltage \& Current vs Time)

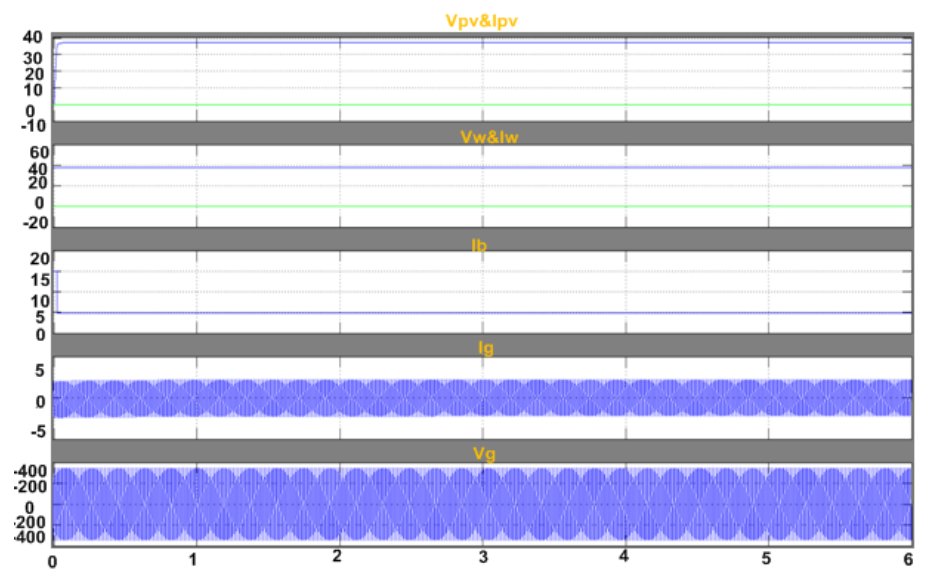

Figure 14. Response of the framework in the absence of both wind and PV source

(Voltage \& Current vs Time)

Table 2. Comparison of THD'S

\begin{tabular}{|c|c|c|c|}
\hline Case .No. & Parameter(Ig) & Variation observed & $(\mathrm{THD} \%)$ \\
\hline Case 1. & Basic model & The PV wind and battery are at stable condition & 0.08 \\
\hline Case 2. & Wind stable with PV increases & The insolation level of PV is increased from $2 \mathrm{~s}$ to $4 \mathrm{~s}$ & 4.55 \\
\hline Case 3. & PV stable with wind increases & The insolation level of wind is increased while PV is stable & 0.13 \\
\hline Case 4. & Wind active PV inactive & $\begin{array}{l}\text { PV is disconnected from } 2 \mathrm{~s} \text { to } 4 \mathrm{~s} \text { and wind is continuous to } \\
\text { operate }\end{array}$ & 0.28 \\
\hline Case 5. & PV active wind inactive & $\begin{array}{l}\text { Wind is disconnected from } 2 \mathrm{~s} \text { to } 4 \mathrm{~s} \text { and } \mathrm{PV} \text { is continuous } \\
\text { to operate }\end{array}$ & 0.46 \\
\hline Case 6. & Both are inactive & Both the sources are disconnected from the supply & 0.38 \\
\hline
\end{tabular}

\subsection{Simulation results of ANFIS}

The Figure 15 shows the rule viewer of ANFIS controller which consist of 2 inputs and 1 output for example input 1 and input 2 is zero the output is 0.469. The Figure 16 shows the surface view of ANFIS controller with inputs ranges from -2 to 2 and one output ranges from 0.2 to 0.8 . The Figure 17 shows the structure of anfis controller with 2 inputs and each input consist of 3 membership functions with set of 9 rules and 9 outputs which are connected to single output. 

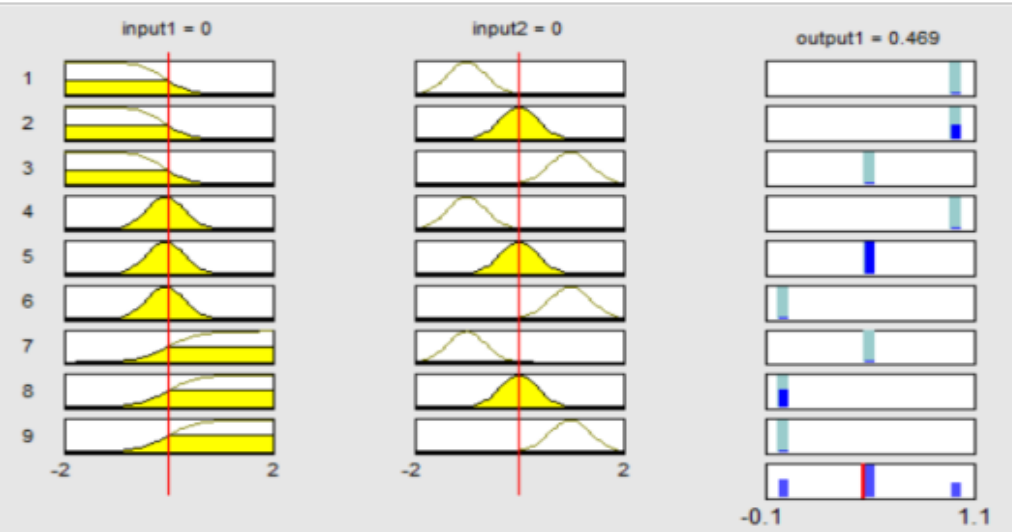

Figure 15. Rule viewer of ANFIS controller

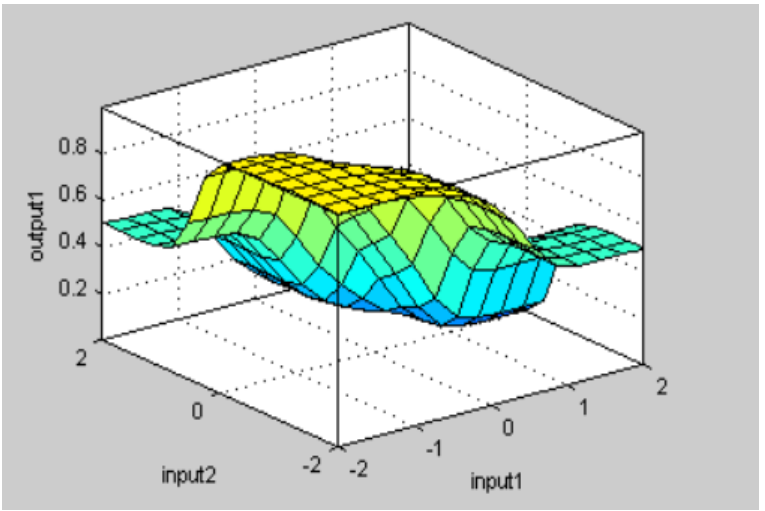

Figure 16. Surface view of ANFIS controller

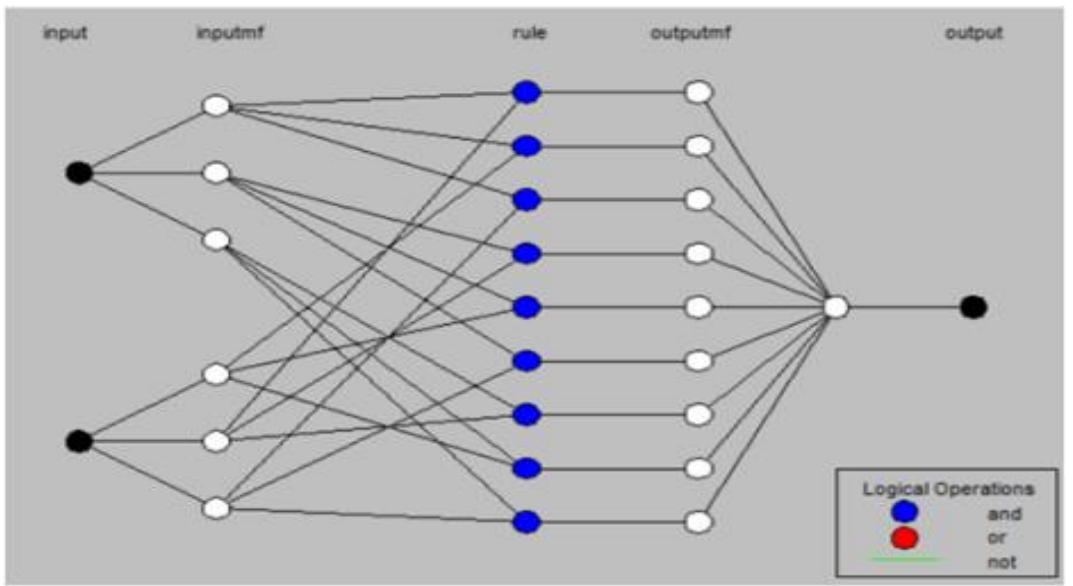

Figure 17. Structure of ANFIS controller

\section{EXPERIMENTAL RESULTS}

The analysis of the photovoltaic module generation system as shown in Figure 18 and its control algorithm presented in Figure 18 are verified using simulation tools in Matlab. A prototype of the entire work is development in the electrical power engineering laboratory. The performance is evaluated on a single PV array system using Arduino microcontroller, hall's effect voltage and current sensors, and single conditioning unit. The gating singles for inverters and converter are obtained using ANFIS pulse width modulation blocks for Arduino controller and an isolation card. 


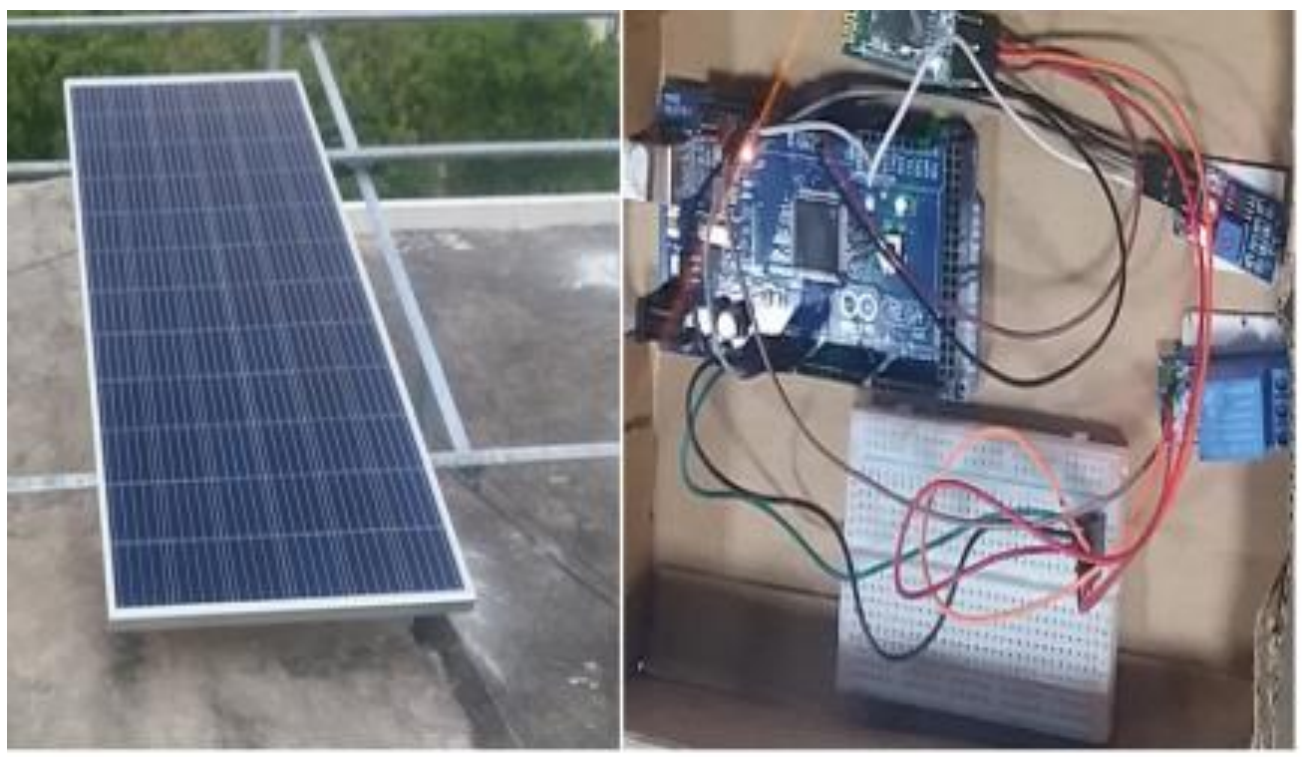

Figure 18. Experimental setup of the part of the proposed work

The experimental result shows in Figure 19 as output variables of voltage and current. It is noted that even in presence of nonlinear balanced load. The grid current and voltage are sinusoidal and balanced. To reach quick convergence and an enhanced THD, the constant parameter is chooses as 5. Hence, the smaller values of constant may contribute to enhance the stability stead state performance but lightly affect the dynamic performance of the control system.

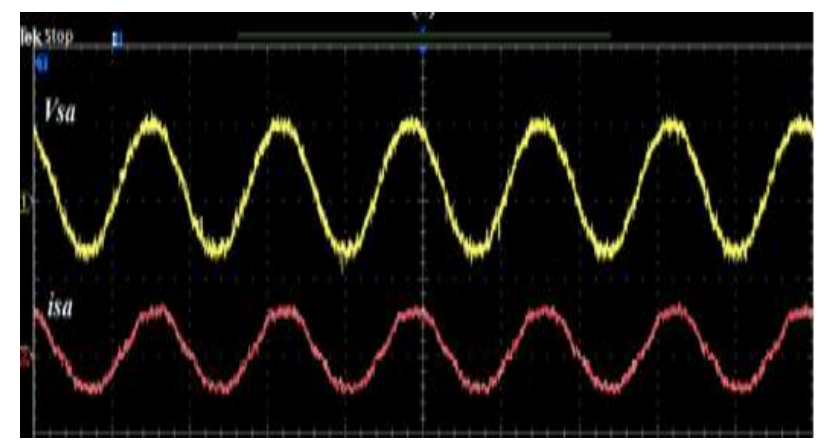

Figure 19. CRO output of inverter voltage and current

\section{CONCLUSION}

A matrix associated cross breed PV-wind-battery based power clearing plan for family unit application is proposed. The proposed half and half system gives an exquisite combination of PV and twist source to remove greatest vitality from the two sources. It is acknowledged by a novel multi-input transformer coupled bidirectional DC-DC converter pursued by a customary full-connect inverter. An adaptable control technique which accomplishes better use of PV, wind control, battery limits without affecting existence of battery and power stream the board in a network associated half and half PV-windbattery based structure sustaining air conditioning loads is displayed. Point by point recreation thinks about is done to find out the practicality of the plan. The recreation results got are in close concurrence with reproductions and are steady in exhibiting the ability of the system to work either in network sustaining or remain solitary mode. The augmentation of Simulation results acquired utilizing MATLAB/Simulink. 


\section{REFERENCES}

[1] F. Valenciaga and P. F. Puleston,"Supervisor control for an independent crossover age framework utilizing wind and photovoltaic vitality," IEEE Trans. Vitality Convers., vol. 20, no. 2, pp. 398-405, Jun. 2005.

[2] C. Liu, K. T. Chau and X. Zhang, "An proficient breeze photovoltaic half breed age framework utilizing doubly energized changeless magnet brushless machine," IEEE Trans. Ind. Electron., vol. 57, no. 3, pp. 831-839, Mar. 2010.

[3] Dr.R.Arulmurugan, Mr.A.Chandramouli ,"Design and usage of a nine-level inverter with shunt dynamic channel for appropriated framework," fourth International meeting on Electrical Energy Systems, Dept. of EEE, SSN College of Engineering, Kalavakkal, Chennai, 07-09 February 2018.

[4] W. Kellogg, M. Nehrir, G. Venkataramanan, and V. Gerez, "Generation unit measuring and cost examination for remain solitary breeze, photovoltaic and cross breed wind/PV systems," IEEE Trans. Ind. Electron., vol. 13, no. 1, pp. 70-75, Mar. 1998.

[5] L. Xu, X. Ruan, C. Mao, B. Zhang, and Y. Luo, "An enhanced ideal estimating technique for wind-sun based battery half breed control framework," IEEE Trans. Feasible Enery., vol. 4, no. 3, pp. 774785, Jul. 2013.

[6] B. S. Borowy and Z. M. Salameh, "Dynamic reaction of an independent breeze vitality change framework with battery vitality stockpiling to a breeze gust," IEEE Trans. Vitality Convers., vol. 12, no. 1, pp. 73-78, Mar. 1997.

[7] S. Bae and A. Kwasinski, "Dynamic displaying and task methodology for a microgrid with wind and photovoltaic assets," IEEE Trans. Keen Grid, vol. 3, no. 4, pp. 1867-1876, Dec. 2012.

[8] C. W. Chen, C. Y. Liao, K. H. Chen and Y. M. Chen, "Modeling and controller plan of a semi confined multi input converter for a half and half PV/wind control charger framework," IEEE Trans. Power Electron., vol. 30, no. 9, pp. 4843-4853, Sept. 2015.

[9] M. H. Nehrir, B. J. LaMeres, G. Venkataramanan, V. Gerez, and L. A. Alvarado, "An way to deal with assess the general execution of remain solitary breeze/photovoltaic creating systems," IEEE Trans. Vitality Convers., vol. 15, no. 4, pp. 433-439, Dec. 2000

[10] W. M. Lin, C. M. Hong, and C. H. Chen, "Neural arrange based MPPT control of an independent half and half power age framework," IEEE Trans. Power Electron., vol. 26, no. 12, pp. 3571-3581, Dec. 2011.

[11] Dr. R. Arulmurugan, "Photovoltaic fueled transformer less half and half converter with dynamic channel for symphonious and receptive power remuneration," ECTI Transactions on Electrical Engineering, Electronics, and Communications, vol.16, no.2, pp.44-51, August 2018.

[12] T. Hirose and H. Matsuo, "Standalone half and half breeze sun powered power age framework applying dump control without dump stack," IEEE Trans. Ind. Electron., vol. 59, no. 2, pp. 988-997, Feb. 2012.

[13] F. Giraud and Z. M. Salameh,"Steady-state execution of a gridconnected housetop half and half breeze photovoltaic power framework with battery capacity," IEEE Trans. Vitality Convers., vol. 16, no. 1, pp. 1-7, Mar. 2001.

[14] W. Qi, J. Liu, X. Chen, and P. D. Christofides, "Supervisory prescient control of independent breeze/sun powered vitality age frameworks," IEEE Trans. Control Sys. Tech., vol. 19, no. 1, pp. 199-207, Jan. 2011.

[15] S. K. Kim, J. H. Jeon, C. H. Cho, J. B. Ahn, and S. H. Kwon, "Dynamic displaying and control of a framework associated half and half age framework with adaptable power transfer," IEEE Trans. Ind. Electron., vol. 55, no. 4, pp. 1677-1688, Apr. 2008.

[16] Arulmurugan, R, "Relative assessment of new FLC controller based MPPT for a DC to DC buck-help zeta converter," WSEAS Transactions on power frameworks, vol.11, pp.27-34, E-ISSN: 2224-350X, 2016.

[17] R. Wandhare and V. Agarwal, "Novel reconciliation of a PV-wind vitality framework with upgraded effciency," IEEE Trans. Power Electron., vol. 30, no. 7, pp. 3638-3649, Jul. 2015.

[18] Dr.R.Arulmurugan, Mr.A.Chandramouli, "PV FLC Approach based Seven Multi-Level Inverter STATCOM for Harmonics Reductions," second International Conference on Smart Computing and Informatics (SCI-2018), Siddhartha Institute of Technology, Vijayawada, Andhra Pradesh, India 27-28 January, 2018.

[19] F. Nejabatkhah, S. Danyali, S. Hosseini, M. Sabahi, and S. Niapour, "Modeling and control of another three-input DC-DC support converter for half breed PV/FC/battery control system," IEEE Trans. Power Electron., vol. 27, no. 5, pp. 2309-2324, Feb. 2014.

[20] Dr.R.Arulmurugan, T.Anushalini, "Execution of Fuzzy Controlling Structure of PV-FC for a Gird Connected System," fourth International meeting on Electrical Energy Systems, Dept. of EEE, SSN College of Engineering, Kalavakkal, Chennai, Joint with IEEE xplorerDOI: 10.1109/ICEES.2018.8443202, 07-09 February 2018. 